\title{
PELATIHAN PEMBUATAN RUNNING TEXT BERBASIS MATRIX DISPLAY LED DENGAN MENGGUNAKAN HD-U6A
}

\author{
Catur Budi Waluyo \\ Program Studi Teknik Elektro \\ Sekolah Tinggi Teknologi Adisutjipto \\ Jl. Janti Blok R Lanud Adisutjipto, Yogyakarta \\ catur_budiwaluyo@yahoo.co.uk
}

\begin{abstract}
The rapid development of electronics technology requires the availability of human resources who have sufficient skills. Students as partners in community service, have participated in LED-based running text design training. The main goal in this community service activity is to improve the skills in the field of electronics and human resources. Targets achieved at this stage is to improve the ability to design and make the program of running text based Led matrix display. The enhancement of designing capability is done through Led-based running text training activity in software and hardware. This activity has been able to achieve the expected goals and targets so that partners can make running text with a more affordable cost.
\end{abstract}

Keywords : Trainning, Running text

\begin{abstract}
Abstrak
Pesatnya perkembangan teknologi elektronika menuntut tersedianya SDM yang mempunyai ketrampilan yang cukup memadai. Untuk itu mahasiswa yang sebagai mitra pengabdian masyarakat ini di laksanakan pelatihan peracangan dan mendesain tulisan berjalan berbasis Led. Tujuan utama dalam kegiatan pengabdian masyarakat ini adalah untuk meningkatkan ketrampilan dalam dunia elektronika serta sumber daya manusia. Target yang dicapai pada tahap ini adalah meningkatkan kemampuan merancang dan memprogram Running Text yang berbasis Matrix Display Led. Peningkatan kemampuan merancang dan mendesain dilakukan melalui kegiatan pelatihan pembuatan running text berbasis Led baik secara software dan hardware. Kegiatan ini telah mampu mencapai tujuan dan target yang diharapkan sehingga mitra dapat membuat tulisan berjalan dengan biaya yang lebih terjangkau.
\end{abstract}

Kata Kunci : Pelatihan, Running Text

\section{Latar Belakang Masalah}

Kehidupan saat ini nyaris tidak lepas dari teknologi, hampir di semua bidang menggunakannya baik dalam hal pendidikan, ekonomi dan budaya. Di zaman yang serba modern ini masyarakat hampir di seluruh dunia memanfaatkan teknologi yang ada, mulai dari menyampaikan pesan dan informasi yang dapat digunakan sebagai sarana iklan juga menampilkan rangkaian tulisan berjalan, serta juga bisa untuk menampilkan gambar dan logo [5-7]. 
LED secara luas dipakai pada modul tampilan ini karena memiliki kelebihan diantaranya tingkat kecerahan tinggi, tegangan kerja rendah, konsumsi daya kecil, miniaturisasi, umur panjang, tahan gangguan dan kinerja yang stabil [2-4]. Tampilan layar LED dan tampilan video terdiri dari blok matriks LED. Display dot matrix dapat menampilkan karakter, teks dan grafis dengan sinkronisasi komputer menggunakan kontrol mikro, grafis, dan gambar untuk memainkan semua jenis informasi secara real-time, sinkron, dan jelas[1][4]

Situasi dalam hal ini yaitu mahasiswa dituntut untuk mendapatkan ketrampilan selain dibangku kuliah demi menyongsong era globalisasi untuk menciptakan terobosan-terobosan baru. Tetapi untuk melakukan hal tersebut tidaklah mudah untuk menyampaikan materi tanpa ada pelatihan terlebih dahulu. Oleh karena itu, untuk tahap ini dilakukan pelatihan pembuatan running text berbasis matrix led display.

Target dan luaran yang diharapkan dari kegiatan pengabdian kepada masyarakat pada usulan ini adalah sebagai berikut:

1. Menumbuhkan minat akan pentingnya perkembangan elektronika.

2. Mengembangkan bakat yang sudah dimiliki menjadi sesuatu yang lebih bermanfaat bagi mahasiswa

3. Menumbuhkan ide-ide kreatif demi terciptanya terobosan-terobosan baru dalam hal dunia elektronika.

\section{Metodologi Pelaksanaan}

Metode yang dipilih untuk meningkatkan kompetensi mahasiswa adalah dengan memberikan pelatihan mendesain dan merakit running text secara software dan hardware. Pelatihan secara software dilaksanakan dengan menggunakan aplikasi HD2016A dan Power Led untuk mendesain tulisan yang akan di unggah dalam running text. Mendesain tulisan dalam program mahasiswa bebas menuangkan ide-ide kreatif untuk memberikan efek animasi tulisan sebelum tulisan / gambar di unggah. Setelah proses mendesain di dalam aplikasi tersebut maka langkah selanjutnya yaitu merakit panel-panel running text tersebut. Setelah perakitan hardware pada panel running text tersebut langkah selanjutnya yaitu mengunggah hasil desain tersebut kedalam perangkat

\section{Hasil, Pembahasan dan Dampak}

Kegiatan pengabdian kepada masyarakat yang berbentuk pemberian pelatihan elektronika yaitu pembuatan running text telah dapat berjalan dengan baik yang sudah dilaksanakan pada tanggal 27 April 2018 di Laboratorium Elektronika Dasar, Sekolah Tinggi Teknologi Adisutjipto. Materi telah dapat diberikan secara untuk mulai mendesain tulisan pada software, perakitan hardware dan pengunggahan tulisan pada perangkat tersebut. Pada umumnya peserta merasa puas dengan kegiatan ini, baik dari segi materi, fasilitas, maupun layanan yang didapat.

a. Penjelasan komponen dan software yang digunakan dalam pembuatan running text

Pengenalan komponen ini di laksanakan dengan instruktur Catur Budi Waluyo.S.T.,M.T. Pengenalan ini diharapkan dapat memberikan pengetahuan tentang komponen yang dibutuhkan dan perkiraan biaya yang di keluarkan dalam pembuatan running text ini. Untuk dokumentasi dapat dilihat pada gambar 1.

b. Pembuatan design dalam software yang digunakan

Pembuatan design dalam software ini di laksanakan dengan instruktur Catur Budi Waluyo,S.T.,M.T dan Rizzan Hazzdiqqi. Pembuatan design dalam software di harapkan mahasiswa menuangkan ide-ide kreatif dalam membuat animasi yang akan digunakan. Untuk dokumentasi dapat dilihat pada gambar 2 . 


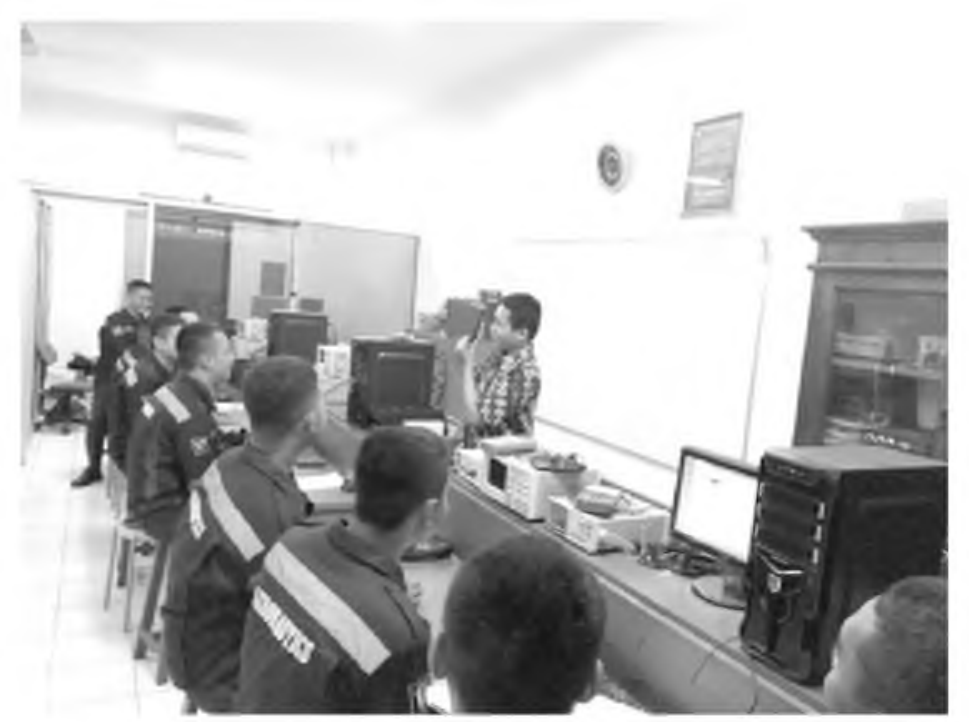

Gambar 1. Penjelasan komponen dan software yang di butuhkan

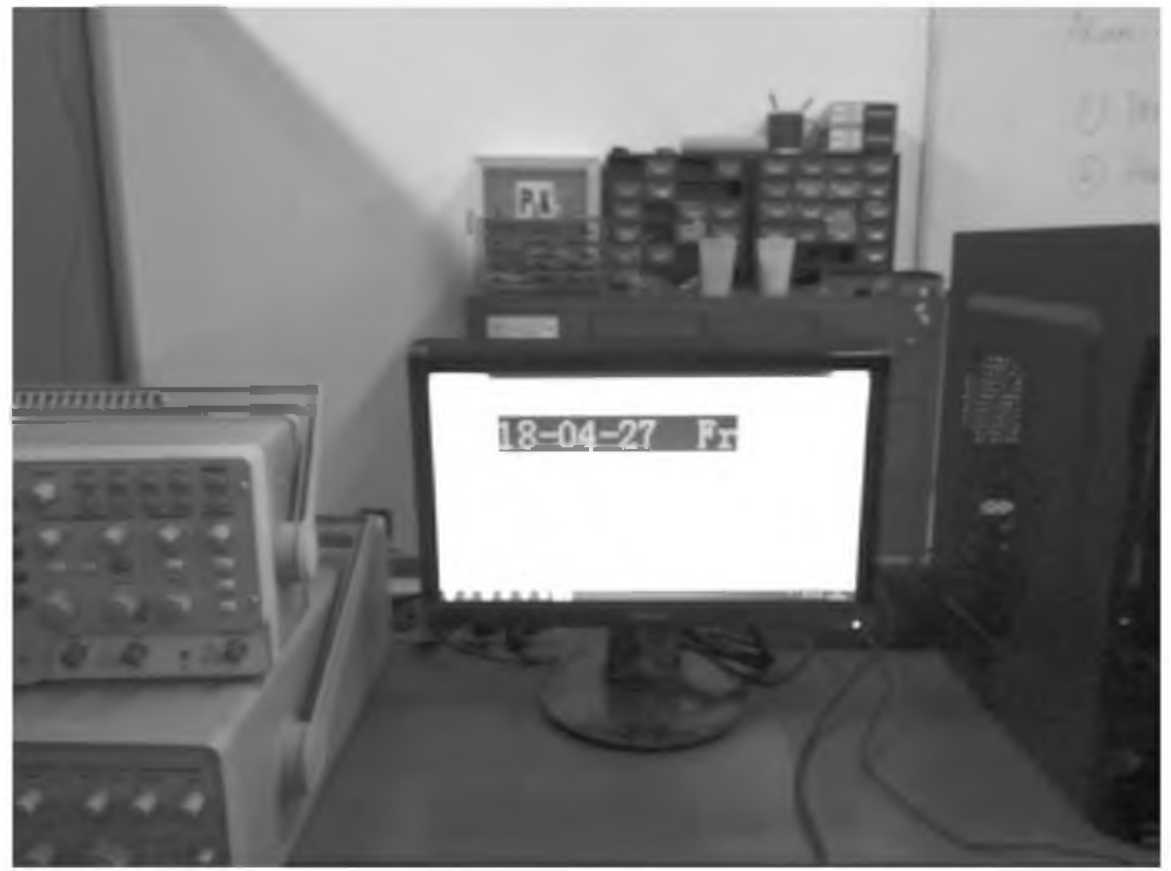

Gambar 2. Pembuatan design text pada software

c. Perakitan komponen-komponen yang digunakan

Langkah selanjutnya yaitu perakitan komponen-komponen sehinga menjadi satu rangkaian yang siap untuk di uji coba dalam penampilan tulisan berjalan. Untuk dokumentasi dapat dilihat pada gambar 3 . 


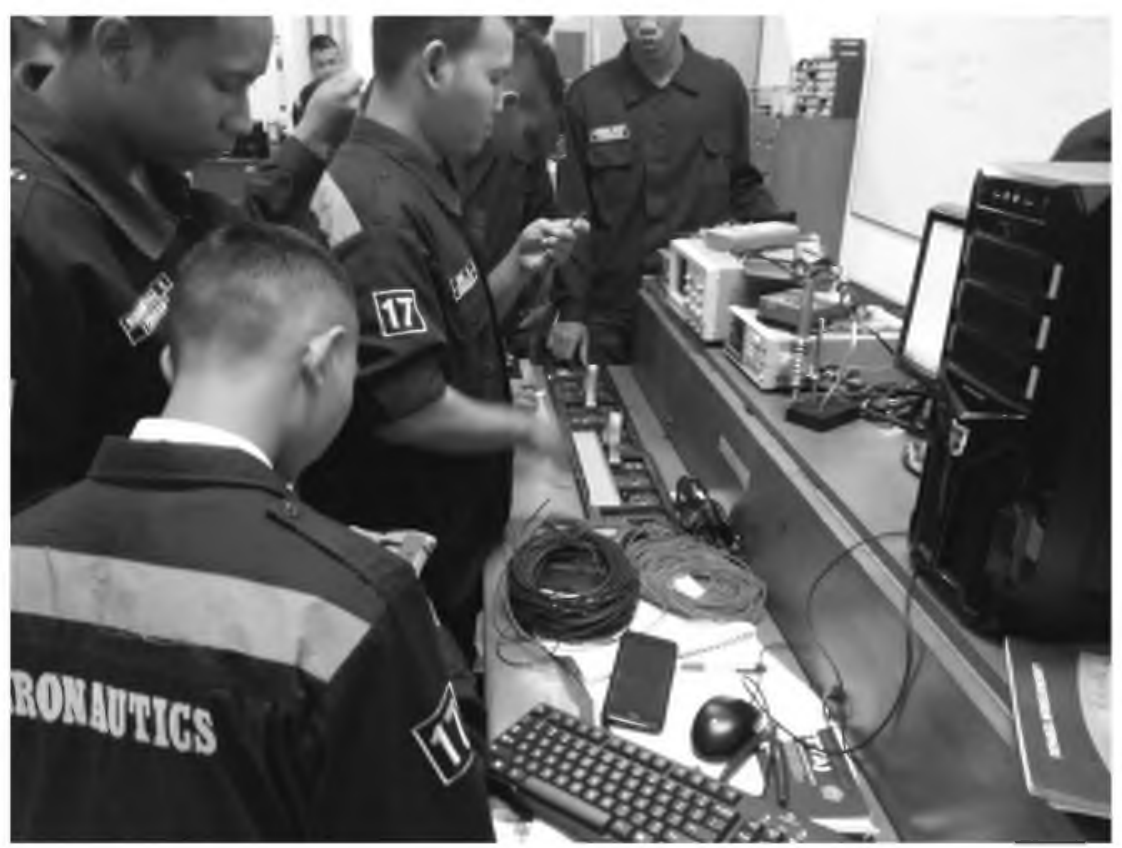

Gambar 3. Proses perakitan hardware

d. Hasil tulisan yang sudah di unggah dalam hardware minning text.

Hasil dari pengunggahan tulisan yang sudah di desain maka akan menampilkan tulisan seperti pada gambar 4 .

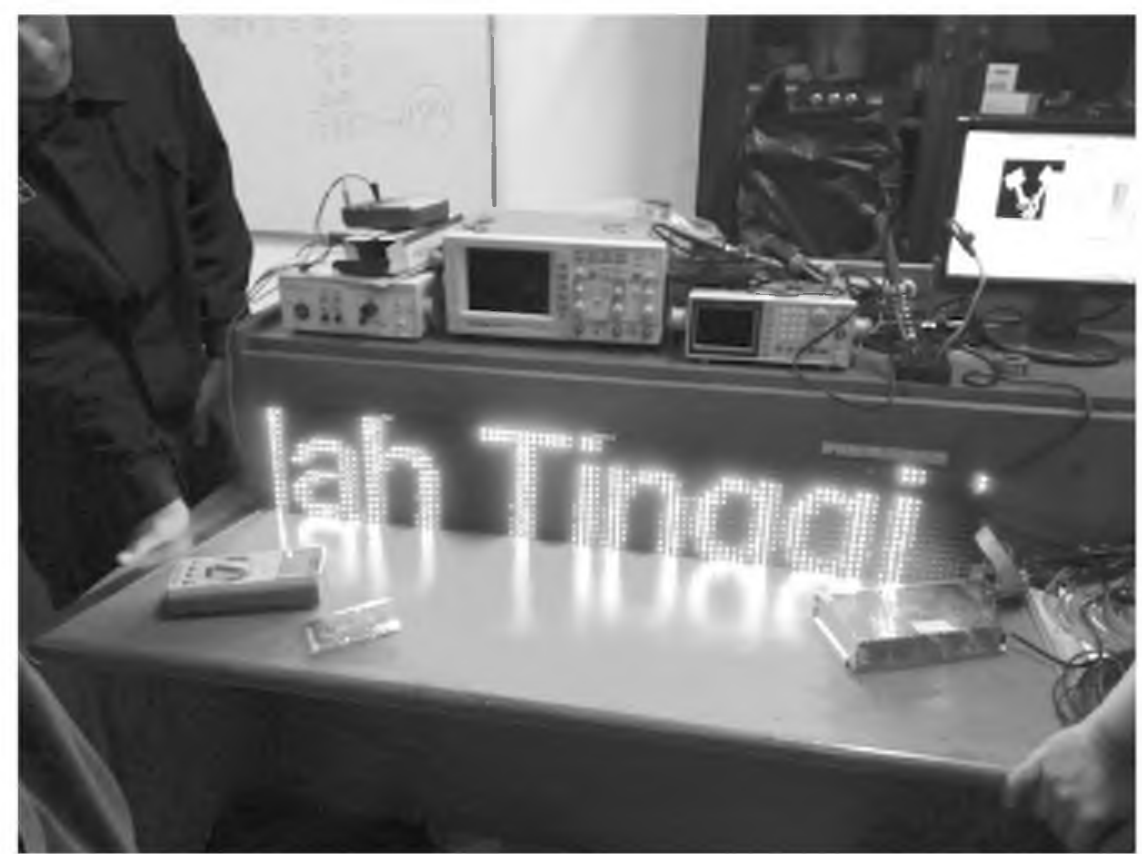

Gambar 4. Hasil Pengunggahan tulisan yang sudah di desain.

Jumlah peserta yang mengikuti pelatihan ini yaitu 23 Orang dan tingkat keaktifan dan minat para peserta pelatihan cukup memuaskan bahkan mereka mengharapkan adanya pelatihan lanjutan setelah kegiatan ini. 


\section{Kesimpulan dan Saran Kesimpulan}

Berdasar pada hasil kegiatan yang telah dipaparkan maka kegiatan pengabdian pada masyarakat ini telah terlaksana dengan baik dan sesuai dengan tujuan yang diharapkan

\section{Saran}

Dari pelaksanaan kegiatan pengabdian ini dapat di ambil beberapa saran yaitu kegiatan ini dapat dilanjutkan dengan kegiatan serupa untuk tahun depan, dan adanya penambahan biaya pendanaan agar hasil pengabdian yang di hasilkan lebih lengkap.

\section{Daftar Pustaka}

[1] Kuang, P. Cao, W. Liu, ZG, 2014. Design of dynamic screen system based on MCU. Wavelet Active Media Technology and Information Processing (ICCWAMTIP), 2014 11th International Computer Conference on,pp. 468 - 470.

[2] Octarina Nur Samijayani dkk, Perancangan Sistem Penulisan Text pada Running Text menggunakan SMS, 2014, Jurnal AL-AZHAR INDONESIA SERI SAINS DAN TEKNOLOGI, Vol . 2, No. 3, Maret 2014

[3] Nugroho A.W. dkk, 2015, Aplikasi Running Text dengan update informasi via SMS, Jurnal Coding, Sistem Komputer Untan Volume 03, No. 2 (2015), hal 23-32, ISSN : $2338-493 x$

[4] Zainuri Ahmad dkk, 2015, Implementasi Bluetooth HC-05 untuk Memperbarui Informasi Pada Perangkat Running Text Berbasis Android, Jurnal EECCIS Vol. 9, No. 2, Desember 2015,

[5] Bogspot,2017, Running Text Moving Sign LED Board Display Reklame, https://www.deprintz.com/news/1/tentang-Running-Text-Moving-Sign-LED-BoardDisplay-Reklame?id=1, di akses 07/12/2017

[6] Blogspot,2017, Tentang Running Text atau Moving Sign, https://jualrunningtextled.wordpress.com/2014/11/10/tentang-running-text-ataumoving-sign/, diakses 07/12/2017

[7] Blogspot,2017, Download dan Install HD2016, http://www.mitraled.com/page/10/Download-Install-HD-2016/, diakses 07/12/2017 
